\title{
Experience of thyroid surgery at tertiary referral centers in Jazan Hospitals, Saudi Arabia
}

\author{
Fahd Alharbi ${ }^{* *}$ and Mohammed Rifaat Ahmed ${ }^{2}$ \\ ${ }^{1}$ Department of Otorhinolaryngology-Head and Neck Surgery, Faculty of Medicine, Jazan, Saudi Arabia \\ ${ }^{2}$ Department of Otolaryngology-Head \& Neck Surgery, Faculty of Medicine, Suez University, Egypt
}

\begin{abstract}
Background: Goitre is a common disease of the thyroid gland with incidence of $15-30 \%$ of the adult population

Objective: The purpose of this study was to evaluate the risks and complication rate of thyroid surgery in Jazan hospitals.

Design: A retrospective study

Settings: Prince Mohammed bin Nasser Hospital and King Fahd Central Hospital, Jazan, Saudi Arabia.

Patients: The data of 310 patients were collected from the data base

Main Outcome Measures: Reviewing and assessment the experience of thyroid surgery at tertiary referral centers
\end{abstract}

Result: Three major complications of thyroid surgery were haemorrhage, recurrent laryngeal palsy, and permanent hypoparathyroidism with varying rates of incidence. Haematoma can cause airway compromise and. In the present study we obtained 31 patients with the three most common complications (9.6\%) and this figure is more or less similar with other reported data of the interest

Conclusion: Proper preoperative preparation and improved surgical technique can reduce the incidence of postoperative complications in thyroid surgery.

\section{Introduction}

Goitre is a common disease of the thyroid gland with incidence of $15-30 \%$ of the adult population [1]. Many retrospective studies evaluated the risks and complication rate of thyroid surgery and found that the three major complications were haemorrhage, unilateral recurrent laryngeal palsy, and permanent hypoparathyroidism with varying rates of incidence [1-3].

Postoperative bleeding may be a devastating complication of thyroid surgery as an unrecognized or rapidly expanding hematoma can cause airway compromise and asphyxiation. The rate of incidence of postoperative bleeding varied from $0.4 \%$ to $1.1 \%$ [2-5].

Temporary and permanent vocal palsy rates were analyzed in many reports and the overall incidences of temporary and permanent vocal palsy were $5.1 \%$ and $0.9 \%$, respectively $[6,7]$.

When irreversible damaged occurred for recurrent laryngeal nerve (RLN), usually patients presented with marked voice dysfunction changes especially in quality as it is complication could be happened following thyroid surgery [7].

Many authors investigated these complication and found ranges from 0.5 to $5 \%$ following thyroidectomy with increased the incidence in both recurrent goiter and total thyroidectomy especially with cancer thyroid [6].

Hypoparathyroidism is another feared complication of thyroid surgery. It may be due to direct trauma to the parathyroid glands, devascularization of the glands, or actual removal of the glands during the thyroid surgery [8]. The reported incidence varies between 0.4 and $13.8 \%$ and is directly correlated to the extent of thyroidectomy [9].

The aim of our study was reviewing and assessment the experience of thyroid surgery at tertiary referral centers in Jazan Hospitals, Saudi Arabia.

\section{Patients and Methods \\ Study site and population}

A retrospective study and was conducted in Prince Mohammed bin Nasser hospital and King Fahd Central Hospital, Jazan, Saudi Arabia.

Information of 320 patients was collected from database in Prince Mohammed bin Nasser hospital and King Fahd Central Hospital, Jazan, Saudi Arabia between January 1, 2011 and January, 2018. All patients, male and females at any age, admitted during that period for thyroid surgery were subjected to the present study. We exclude the patients whose data was in complete. The following parameters were obtained:

${ }^{*}$ Correspondence to: Fahd Alharbi, MD, Professor Otolaryngology, faculty of medicine, Jazan, Saudi Arabia, Tel: +966- 54- 3043452, E-mail: fahdalharbi3@ gmail.com

Key words: goiter, thyroid nodule, thyroidectomy, complications, Saudi Arabia

Received: April 14, 2018; Accepted: April 22, 2018; Published: April 28, 2018 


\section{1-Operative mortality}

2-Major complications: Bleeding, Recurrent laryngeal nerve injury and Hypoparathyroidism.

\section{Study plan}

1- The vocal cords status for the patients was checked preoperatively by direct rigid laryngoscope (Rigid laryngeal endoscope, Storz $70^{\circ}$ with video monitor).

2- Investigations: neck ultrasound, determination of free T3, free $\mathrm{T} 4$, thyroid stimulating hormone and serum calcium concentration, and fine-needle aspiration cytology.

3- Postoperative periods follow up including: Status of Laryngeal nerves (by direct rigid laryngoscope), the function of parathyroid was checked immediately in the postoperative period by serum calcium concentration and parathyroid hormone level.

\section{Statistical analysis}

Data collected were processed using SPSS version 15 (SPSS Inc., Chicago, IL, USA). Quantitative data were expressed as means \pm SD while qualitative data were expressed as numbers and percentages.

\section{Ethical considerations}

The local ethics committee approved the study. Written consent was obtained from all patients or first degree relatives before the management procedure.

\section{Results}

The patients were categorized according to pre and postoperative data as shown in table 1.

The following criteria were reported

1-Operative mortality: One patient died from asphyxia due to large wound haematoma

2-Major complications: The three major complications were seen with different percentage in all types of operations whether, hemithyroidectomy, total thyroidectomy or completion thyroidectomy (Table 2).

A- Bleeding: We observed that postoperative haemorrhage was seen in 4 patients (1.25\%) with reported one death from asphyxia due to large wound haematoma.

B- Recurrent laryngeal nerve injury: The total number of patients with recurrent laryngeal nerve injuries was 10 out of 31 major complications and was more evident in case of total thyroidectomy that represented $25 \%$ of its major complications (2/8).

C- Hypoparathyroidism: The total number of patients with hypoparathyroidism was 17 out of 31 major complications and was also more evident in case of total thyroidectomy that represented 37.4 $\%$ of its major complications (3/8).

\section{Discussion}

The mortality rate from thyroid surgery during the 1800 s was around $40 \%$ as these mortalities were due to infection and hemorrhage but recently, the incidence of death ranges from zero to $0.5 \%[2,4,10]$.

Thyroid surgery in recent years is generally considered quite safe owing to better preoperative preparation and improved surgical
Table 1. Shows categorization of patients according to diagnosis of goiter

\begin{tabular}{|c|c|c|}
\hline Goitre & Numbers & $\mathbf{\%}$ \\
\hline I) Solitary nodule & 188 & 58.75 \\
\hline II) Multinodular & 124 & 38.75 \\
\hline III) Malignant & 8 & 2.50 \\
\hline
\end{tabular}

Table 2. Shows major complications in relation to diagnosis of goitre with significant distribution. $[\mathrm{p}<0.5]$

\begin{tabular}{|c|c|c|c|c|}
\hline Complications & $\begin{array}{c}\text { Solitary } \\
\text { nodule }\end{array}$ & Multinodular & Malignant & Total \\
\hline Bleeding & 1 & 2 & 1 & 4 \\
\hline Nerve injury & 4 & 4 & 2 & 10 \\
\hline Hypoparathyroidism & 1 & 13 & 3 & 17 \\
\hline Total & 6 & 19 & 6 & 31 \\
\hline
\end{tabular}

Table 3. Shows percentages of major complications in relation to diagnosis of goiter.

\begin{tabular}{|c|c|c|c|}
\hline Goitre & Total numbers & complications & \% \\
\hline Solitary nodule & 188 & 6 & 3.19 \\
\hline Multinodular & 124 & 19 & 15.32 \\
\hline Malignant & 8 & 6 & 75 \\
\hline
\end{tabular}

techniques that kept complications at a minimum level to less than $2-3 \%$ [11]. Our data came in agreement with these figures as we found one death only in 320 patients.

Post thyroidectomy haematoma leading to airway problem is rare but can be fatal and remains a surgical challenge for the operating team due to the life-threatening acute asphyxia $[11,12]$. It was reported that the most common cause of post-thyroidectomy haemorrhage was bleeding from the thyroid lobe stump and the most dangerous haemorrhage, because of its intensity, was the bleeding from the superior thyroid artery $[13,14]$.

The rate of postoperative haemorrhage varied from $0.56 \%$ to $1.1 \%$ as reported in many series $[3,4,11-13,15]$ while others described their experiences of thyroidectomies with hemorrhage up to $2.5 \%$ [14]. In the present study we noticed that postoperative haemorrhage was seen in 4 patients (1.25\%), which is in concordance with many reports, and one patient died from airway obstruction due to large hematoma.

The frequency of recurrent laryngeal nerve (RLN) injury ranges from 0.5 to $5 \%$ in different medical centres and increases in case of both completion thyroidectomy and total thyroidectomy due to thyroid cancer. The nerve lesion varies from irreversible, persistent and transient dysfunction with good prognosis of complete recovery from several weeks to two years [7,16-18].

In the light of law and medical aspects, we recommended obligatory preoperative laryngological examination with the evaluation of vocal folds mobility and on the 3rd post-operative day in order to identify early RLN lesion. Permanent RLN paralysis may be diagnosed on the basis of multiple laryngological examinations in the period between 3 and 24 months after surgery [16].

In the present study we noticed that postoperative recurrent nerve injury was seen in 10 patients $(3.12 \%)$ that came in agreement with many reports. Recovery was observed in 6 patients and the remainders unfortunately lost follow up.

The incidence of hypocalcaemia will depend on the type of surgery performed. After thyroidectomy for large multinodular goitre, temporary hypocalcaemia requiring calcium replacement occurred in $20 \%$ of patients. This usually occurs about $36 \mathrm{~h}$ postoperatively. Only up to $3 \%$ of patients had persistent hypocalcemia [19]. 
Another study reported postoperative hypocalcemia with rate of $4.7 \%$ that persists in $1.3 \%$ of patients [4]. Chronic hypoparathyroidism with unrecovered normal function after six months was reported in $1.4 \%$ of cases and seen in more extensive type of surgery $[19,20]$.

In the present study we noticed that postoperative hypocalcaemia was seen in 17 patients (5.3\%) that came in agreement with many reports. Chronic hypoparathyroidism with unrecovered normal function for more than six months was observed in 5 patients $(1.6 \%)$ and the remainders showed complete recovery with time.

The overall postoperative complications of thyroid surgery occurred up to $12 \%$ of patients in many available reports $[21,22]$, but may be kept at a minimum to less than 2-3\% [11]. In the present study we obtained 31 patients with the three most common complications (9.6\%) and this figure is more or less similar with other reported studies.

\section{Conclusion}

Proper preoperative preparation and improved surgical technique, the use of nerve monitoring and magnification loop glasses, all can reduce the incidence of post-operative complications in thyroid surgery. Experienced surgeons with careful observation of his patients before discharge are necessary to reduce these complications.

\section{Conflict of Interest}

We declare that there is no conflict of interest.

\section{References}

1. Farling PA (2000) Thyroid disease. Br J Anaes 85: 1 15-28.

2. Dener C (2002) Complication rates after operations for benign thyroid disease. Acta Otolaryngol 122: 679-683. [Crossref]

3. Benzarti S, Miled I, Bassoumi T, Ben Mrad B, Akkari K, et al. Thyroid surgery (356 cases): risks and complications. Rev Laryngol Otol Rhinol (Bord) 123: 33-7. [Crossref]

4. Ignjatovic M, Cuk V, Ozegovic A, Cerović S, Kostić Z, et al. (2003) Early complications in surgical treatment of thyroid diseases: analysis of 2100 patients. Acta Chir Iugosl 50: 155-75. [Crossref]

5. Pelizzo MR, Toniato A, Piotto A, Bernante P, Pagetta C, et al. (2001) [Prevention and treatment of intra- and post-operative complications in thyroid surgery]. Ann Ital Chir 72: 273-276. [Crossref]

6. Randolph GW, Kobler JB, Wilkins J (2004) Recurrent laryngeal nerve identification and assessment during thyroid surgery: laryngeal palpation. World J Surg 28: 755-60. [Crossref]
7. Chiang FY, Lee KW, Huang YF, Wang LF, Kuo WR (2004) Risk of vocal palsy after thyroidecitomy with identification of the recurrent laryngeal nerve. Kaohsiung $\mathrm{J} \mathrm{Med}$ Sci 20: 431-436. [Crossref]

8. Meyer T, Merkel S, Radespiel-Troeger M, Hohenberger W (2002) [Dysfunction of calcium metabolism following resection of the thyroid gland. An analysis of important risk factors]. Zentralbl Chir 127: 429-34. [Crossref]

9. Trupka A, Sienel W (2002) [Autotransplantation of at least one parathyroid gland during thyroidectomy in benign thyroid disease minimizes the risk of permanent hypoparathyroidism]. Zentralbl Chir 127: 439-442. [Crossref]

10. Bhansali SK, Chandalia HB (2002) Thyrotoxicosis - Surgical Management in the Era of Evidence-based Medicine: Experience in Western India with 752 Cases. Asian J Surg 25: 291-9. [Crossref]

11. Savargaonkar AP (2004) Post-thyroidectomy haematoma causing total airway obstruction - A Case Report. Indian J Anaesth 48: 483-485.

12. Röher HD, Goretzki PE, Hellmann P, Witte J (1999) [Complications in thyroid surgery. Incidence and therapy]. Chirurg 70: 999-1010. [Crossref]

13. Cichon S, Anielski R, Orlicki P, et al. (2005) [Post-thyroidectomy hemorrhage]. Przegl Lek 59: 489-92.

14. Agarwal A, Mishra SK (1997) Post-thyroidectomy haemorrhage: an analysis of critical factors in successful management. J Indian Med Assoc 95: 418-9, 433. [Crossref]

15. Chen WJ, Deng Y, Liang ZY (2003) Acute respiratory obstruction during thyroid operation: analysis of 10 cases. Di Yi Jun Yi Da Xue Xue Bao 23: 507-509. [Crossref]

16. Jamski J, Jamska A, Graca M, Barczyński M, Włodyka J (2004) Recurrent laryngeal nerve injury following thyroid surgery]. Przegl Lek 61: 13-6. [Crossref]

17. Otto RA, Cochran CS (2002) Sensitivity and specificity of intraoperative recurrent laryngeal nerve stimulation in predicting postoperative nerve paralysis. Ann Otol Rhinol Laryngol 111: 1005-7. [Crossref]

18. Robertson ML, Steward DL, Gluckman JL, Welge J (2004) Continuous laryngeal nerve integrity monitoring during thyroidectomy: does it reduce risk of injury? Otolaryngol Head Neck Surg 131: 596-600. [Crossref]

19. Debry C, Schmitt E, Senechal G, Silisté CD, Quevauvilliers J, et al. (1995) [Analysis of complications of thyroid surgery: recurrent paralysis et hypoparathyroidism. On a series of 588 cases]. Ann Otolaryngol Chir Cervicofac 112: 211-7. [Crossref]

20. Glinoer D, Andry G, Chantrain G, Samil N (2000) Clinical aspects of early and late hypocalcaemia afterthyroid surgery: Eur J Surg Oncol 26: 571-7. [Crossref]

21. Huang SM, Lee CH, Chou FF, Liaw KY, Wu TC; Taiwan Endocrine Surgeons Study Group (2005) Characteristics of thyroidectomy in Taiwan. J Formos Med Assoc 104: 6-11. [Crossref]

22. Acun Z, Cihan A, Ulukent SC, Comert M, Ucan B, et al. (2004) A randomized prospective study of complications between general surgery residents and attending surgeons in near-total thyroidectomies. Surg Today 34: 997-1001. [Crossref]

Copyright: (C2018 Alharbi F. This is an open-access article distributed under the terms of the Creative Commons Attribution License, which permits unrestricted use, distribution, and reproduction in any medium, provided the original author and source are credited. 